\title{
Pasteurella pneumotropica: meningitis following a dog bite
}

\author{
E.J. Minton \\ Infectious Diseases Unit, City Hospital, Edinburgh, UK.
}

Summary: A 38 year old man developed meningitis following a dog bite. Pasteurella pneumotropica, usually an animal pathogen, was isolated from the cerebrospinal fluid. The patient made a complete recovery after antibiotic therapy. The relevant literature is reviewed.

\section{Introduction}

Pasteurella pneumotropica is usually an animal pathogen, which rarely causes infection in humans. I report a case of $P$. pneumotropica meningitis following a dog bite.

\section{Case report}

A 38 year old unemployed labourer was admitted with a 5 day history of severe frontal headache, nausea, vomiting, malaise and back pain, after a head injury sustained in a fight. He had been bitten by a dog a few days before admission. His past medical history consisted of a blackout a few months previously which was thought to be alcohol related. He had a 15 year history of alcohol abuse, drinking on average 15 pints per night. On examination he was pyrexial at $39.2^{\circ} \mathrm{C}$. He had marked neck stiffness, but was alert and orientated with no photophobia. He had superficial lacerations over his nose, right ear and cheek and there was a recent dog bite on the right thumb. The pulse rate was 130 beats/minute and the blood pressure $130 / 80 \mathrm{mmHg}$. Lumbar puncture revealed cloudy cerebrospinal fluid (CSF) with 1900 neutrophils per cubic $\mathrm{mm}$, glucose $<1 \mathrm{mmol} / \mathrm{l}$ and protein $4008 \mathrm{mg} / \mathrm{l}$. No organisms were seen on Gram staining. Routine blood tests showed white cell count $6.8 \times 10^{9} / 1$, haemoglobin $11.4 \mathrm{~g} / \mathrm{l}, \mathrm{MCV}$ $91.4 \mathrm{fl}$, platelets $495 \times 10^{9} / 1$, urea $2.1 \mathrm{mmol} / \mathrm{l}$, gamma glutamyl transferase $236 \mathrm{U} / 1$, with other liver function tests normal. Blood glucose on admission was $6.2 \mathrm{mmol} / \mathrm{l}$.

A diagnosis of bacterial meningitis was made. As light microscopy of the cerebrospinal fluid had not

Correspondence: E.J. Minton, M.R.C.P., Norfolk \& Norwich Hospital, Brunswick Road, Norwich NR1 3SR, UK.

Accepted: 27 June 1989 shown any organisms, the patient was empirically started on intravenous benzyl penicillin and chloramphenicol. Flucloxacillin was added in case of staphylococcal infection of the facial lacerations. Within 24 hours the pyrexia had settled and the patient was clinically much improved. Culture of the CSF yielded a growth of a pleomorphic Gramnegative bacillus, identified as Pasteurella pneumotropica using the API 20 NE System kit. The organism was not recovered from blood cultures. The organism was sensitive to chloramphenicol, ampicillin, erythromycin, cotrimoxazole and Augmentin (amoxycillin and clavulinic acid). Once the sensitivity results were available, the patient was treated with Augmentin alone rather than chloramphenicol, because of the known risks of hepatic and bone marrow toxicity. The patient made an uneventful recovery and remained well when reviewed in the outpatient clinic 6 weeks later.

\section{Discussion}

The genus Pasteurella comprises a group of Gramnegative pleomorphic bacteria which are primarily animal pathogens. Pasteurella multocida is the organism most commonly associated with human infections, usually isolated from infected dog bites. It can also cause septicaemia in patients with hepatic dysfunction, sometimes with metastatic seeding including meningitis. ${ }^{1}$ Pasteurella pneumotropica was first isolated from laboratory mice in 1950 by Jawetz, ${ }^{2}$ and was so named because of characteristic lung lesions. It has since been isolated from rats, cats and dogs. Eleven cases of human infection with $P$. pneumotropica have been reported to date, of which 7 had direct contact with animals. Of these, 2 patients had $P$. pneumotropica meningitis, ${ }^{3}$ the other cases being infected dog bites, ${ }^{4,5}$ septicaemic shock, ${ }^{6}$ upper respiratory tract 
infection, ${ }^{7}$ and osteomyelitis with arthritis. ${ }^{8}$

Meningitis very rarely occurs as a complication of a dog bite. One other organism has been implicated in addition to $P$. pneumotropica and $P$. multocida. A Gram-negative rod known as DF-2 (dysgonic fermenter) present in the oropharynx of dogs, has been isolated in 4 cases of meningitis ${ }^{9}$ in dog handlers. Whether or not these patients were bitten is not documented.

This patient presumably became infected with $P$.

\section{References}

1. Weber, D.J., Wolfson, J.S., Swartz, M.N. \& Hooper, D.C. Pasteurella multocida infections: report of 34 cases and review of the literature. Medicine (Baltimore) 1984, 63: 133-154.

2. Jawetz, E. A pneumotropic Pasteurella of laboratory animals. 1. Bacteriological and serological characteristics of the organism. J Infect Dis 1950, 86: 172-183.

3. Cooper, A., Martin, R.\& Tibbles, J.A.R. Pasteurella meningitis. Neurology 1973, 23: 1097-1100.

4. Medley, S. A dog bite wound infected with Pasteurella pneumotropica, Med J Aust 1977, 2: 224-225.

5. Winton, F.W. \& Mair, N.S. Pasteurella pneumotropica isolated from a dog-bite wound. Microbios 1969, 2: 155- 162.

6. Rogers, B.T., Anderson, J.C., Palmer, C.A. \& Henderson, W.G. Septicaemia due to Pasteurella pneumotropica. J Clin Pathol 1973, 26: 396-398. pneumotropica following the dog bite. It is possible that his high alcohol consumption caused some degree of hepatic dysfunction and immunosuppression ${ }^{10}$ predisposing him to this unusual infection.

\section{Acknowledgements}

I thank Dr R.P. Brettle and Dr P.D. Welsby for permission to report this case, and Dr B. Watt and staff of the Bacteriology Laboratory, City Hospital, Edinburgh.

7. Miller, J.K. Human pasteurellosis in New York State. $N Y$ State J Med 1966, 66: 2527-2531.

8. Gadberry, J.L., Zipper, R., Taylor, J.A. \& Wink, C Pasteurella pneumotropica isolated from bone and joint infections. J Clin Microbiol 1984, 19: 926-927.

9. Butler, T., Weaver, R.E., Venkata Ramani, T.K. et al. Unidentified Gram-negative rod infection: a new disease of man. Ann Int Med 1977, 86: 1-5.

10. Eichner, E.R. The haematological disorders of alcoholism. Am J Med 1973, 54: 261-630. 